The Space Encycloprdia

A Guide to Astronomy and Space Research. Second, revised edition. Pp. 288. (Horsham: The Artemis Press, 1960.) 35s.

$7 \mathrm{HE}$ first edition of this fascinating work was published just before the launching of Sputnik 1. Much that was then mere speculation is now accomplished fact, and the many alterations in the new edition reflect the present rapid advance in space research. The section on "Artificial Satellites" has been completely re-written, with details of the 25 satellites and space probes launched prior to April 1960. The forty-odd new sections, ranging from "Black Knight" to "Van Allen Belts", have been added at the expense of certain minor topics and the condensation of others. In particular, several missiles hitherto treated separately are now collected under the new heading "Missile".

The appearance of the book is much improved by the addition of eight colour plates, one of which shows the beautiful "Veil Nebula in Cygnus". The famous Russian "Far side of the Moon" is one of several new photographs.

Certain misprints persist. In the Table of Planets, p. 230, the masses of Mars to Neptune are incorrect and on p. 155 the period of Phobos is still given as $7 \mathrm{~d}$. $39 \mathrm{~m}$. A curious mistake also occurs in the diagram on p. 28, where the track of Sputnik 1 is shown starting off south-east instead of north-east. These errors apart, the Space Encyclopoedia will provide a useful reference to space enthusiasts for the next year or two, when we shall look forward to a further revised edition.

R. H. Merson

\section{Principles of Electricity and Magnetism}

By Y. Rocard. Translated by G. F. Herrenden Harker. Pp. $x+779$. (London: Sir Isaac Pitman and Sons, Ltd., 1959.) 70s. net.

A NEW book in this field would need to be outstanding to make the task of translating worth while. The book is very up to date, and the many examples of the practical uses of the topics discussed bring new life into what is often regarded as a dull, text-book subject. Although the author advocates the use of rationalized M.K.S. units he in fact uses e.s.u., e.m.u., and practical units. The scope of the book is much wider than is implied by the title. Some sections have become so condensed that they have little value. The section on X-rays, which seems out of place in this volume, contains a number of mistakes (for example, it is suggested that a Laue photograph is obtained with a stationary crystal and monochromatic radiation, and, later, a powder diagram is described as a Laue photograph).

The Grenoble electrostatic generator is described in considerable detail, but no information is given about its performance. It is encouraging to see the permalloy magnetometers included in this type of book. The chapters on polyphase currents and d.c. machines are more complete than one expects in a book aimed at physicists rather than engineers. The notation throughout the book is not uniform. In Chapter 13 the Langevin formula is given and the symbols used are defined. In Chapter 31 the detailed theory is given using a different set of symbols. It is a pity, in a book designed for undergraduates, to find no problems for the students to solve.

E. STANLey
Proceedings of the Institute of Petroleum Hydrocarbon Research Group Conference on Molecular Spectroscopy

Held in London, 27-28 February, 1958. Edited by E. Thornton and Dr. H. W. Thompson. Pp. vii + 352. (London and New York: Pergamon Press, 1959.) 70s. net.

7 HIS report gives the twenty-two papers presented 1 together with the relevant discussion at the second two-day conference on molecular spectroscopy held by the Hydrocarbon Research group. The contributors are from both industrial and academic laboratories in several countries, and are leaders in fields ranging from nuclear magnetic resonance through infra-red to ultra-violet spectroscopy, able to discuss with authority new ideas and techniques.

The range of topics presented is far from being confined to the petroleum field and will be of interest to every physical and organic chemist. The extent to which the conference is topical is demonstrated by the high proportion of space devoted to nuclear magnetic resonance spectroseopy and other new fields, for example, the applications of polarized infra-red radiation, shock-tube excitation and freeradical spectra. A range of papers shows advances in the infra-red region, including new instrumentation, theories of band intensities and the study of intermolecular forces in compressed gases, in surface adsorption, in solution and in the formation of hydrogen bonds.

The organizers of the conference are to be complimented on bringing this interesting diversity of speakers together. However, it does seem that the fields covered by the heading of "Molecular Spectro. scopy" are rapidly becoming too numerous and too specialized to be covered adequately in a two-day meeting.

A. KNOWLES

A Mathematical Tool-Kit for Engineers

By H. A. Webb and Dr. D. G. Ashwell. Second edition. Pp. vii + 116. (London: Longmans, Green and Co., Ltd., 1959.) 158.

AONCISE account of the more importani A mathematical topies dealt with in the final year of engineering undergraduate courses is published, in second edition, under the intriguing title A Mathematical Tool Kit for Engincers. This title is truly descriptive of the book. Within the compass of little more than one hundred pages, eleven chapters deal with complex numbers, differential equations, Fourier series and Bessel functions, together with the calculus of variations and the theory of errors. A chapter on Macaulay methods discusses a littleknown technique for discontinuous differential equations, and the Laplace transform is associated, through the integral inversion formula, with a chapter on contour integration. The most important basic formulæ, in relation to engineering application, are derived as simply and directly as possible, without, of course, any attempt at mathematical rigour, and techniques of application are suitably illustrated. That arguments presented with such conciseness and economy can still carry conviction is a tribute to the skill and ingenuity with which the derivations have been devised and developed. The selection of material is excellent. The little book should be of great value to engineering undergraduates and, as a work of occasional ready reference, to practising engineers.
J. Greig 